\title{
"UMA PÁ DE OCUPAÇÃO": Ocupações escolares e atuação juvenil no Rio Grande do Sul (2016)
}

\author{
Bárbara Virgínia Groff da Silva \\ Eduardo Cristiano Hass da Silva ${ }^{(*)}$ \\ Acordei olhei pro lado \\ Vi manifestação \\ E do outro lado vi \\ Uma pá de ocupação \\ Letra da música Ocupar e Resistir - Koka e Fabricio Ramos ${ }^{l}$
}

\section{PENSANDO AS OCUPAÇÕES ESCOLARES}

Este artigo apresenta algumas reflexões sobre as ocupações das escolas secundárias ocorridas no Rio Grande do Sul a partir do mês de maio de 2016. O enfoque é pensar esses acontecimentos a partir da ideia de juventudes e das culturas juvenis, bem como refletir sobre essas experiências para as trajetórias desses jovens estudantes secundaristas que estão envolvidos politicamente com a melhora da educação pública tanto estadual quanto nacional. As ocupações das escolas gaúchas não são movimentos isolados. Em 2015, ocorreram experiências similares em outros estados, como São Paulo, e atualmente ocorrem experiências parecidas no Rio de Janeiro e Goiás. Após embates políticos e negociações dos jovens secundaristas, professores, funcionários, responsáveis e governo do estado, algumas reivindicações estudantis foram negociadas e acordos foram firmados entre as partes para as desocupações dos espaços escolares.

Para pensarmos as ocupações escolares, é importante utilizarmos o conceito de juventudes. Os sujeitos que estão na fase da vida definida socialmente como juventude ${ }^{2}$ são plurais e possuem trajetórias e vivências que os diferenciam. Portanto, não podem ser pensados de forma singular,

\footnotetext{
${ }^{(*)}$ Bárbara Virgínia Groff da Silva. Mestra em Educação pela Pontifícia Universidade Católica do Rio Grande do Sul (PUCRS). Graduada em História pela Universidade Federal do Rio Grande do Sul (UFRGS). Professora da rede estadual de ensino do Rio Grande do Sul. E-mail: barbara.vgs@gmail.com.

Eduardo Cristiano Hass da Silva. Mestre em História pela Pontifícia Universidade Católica do Rio Grande do Sul (PUCRS). Graduado em História pela Pontifícia Universidade Católica do Rio Grande do Sul (PUCRS). E-mail: eduardo.cristiano@acad.pucrs.br.

1 Essa música foi composta durante as manifestações estudantis de São Paulo e está disponível em: <https://www.youtube.com/watch?v=PqiHEh1ly6U>. Acesso em: 16 jan. 2017.

${ }^{2}$ As fases da vida são construções históricas que se modificam ao longo do tempo (ver Ariès (1981, p. 40)). No caso brasileiro, o Estatuto da Juventude (lei $n^{\circ}$ 12.852/2013) define como jovens as pessoas entre 15 e 29 anos (BRASIL, 2013).
}

Revista Teias v. 18, n. 50, 2017 (Jul./Set.): Conversas sobre formação de professores, práticas e currículos 
como um grupo coeso (DAYRELL; CARRANO, 2014, p. 103). A juventude como uma moratória, tempo de aprendizado, estudo, fruição e amadurecimento, não está disponível para todos os sujeitos jovens. Existem diferentes situações juvenis e aspectos como condições socioeconômicas, de gênero, étnico-raciais são condicionantes que transformam as vivências desses sujeitos (MARGULIS; URRESTI, 2008, p. 28). Dessa forma, concordamos com Laranjeira, Iriart e Rodrigues (2016) quando afirmam que as juventudes podem ser pensadas como uma categoria social, pois

[...] admitimos a sua posição na ordenação da sociedade, não como mera passagem para a vida adulta, mas como grupo que tensiona os espaços sociais e geracionais, numa conjuntura em que as formas de participação, os cenários políticos, a organização do trabalho se transformam rapidamente (LARANJEIRA; IRIART; RODRIGUES, 2016, p. 119).

Essa multiplicidade de sujeitos está em movimento e, no caso das ocupações escolares, está tensionando diretamente os espaços sociais e geracionais. Ocupar as escolas é um ato político e uma novidade, pois os estudantes modificam a forma de lutar pela educação e trazem novos olhares para a escola e para a utilização do espaço escolar. Essas atitudes reverberam em todos que pertencem aquela instituição de ensino. Não há como ficar passivo ou indiferente diante das atitudes, discursos e modos de fazer política desses jovens ocupantes.

\section{2. "E SE A GENTE OCUPASSE A ESCOLA?": EXEMPLOS DE SÃO PAULO E CHILE.}

A pergunta que está no subtítulo foi retirada do documentário "Acabou a Paz, isto aqui vai virar o Chile!"3, quando um jovem da Escola Estadual Diadema, em São Paulo, comenta como surgiu a ideia de modificar a forma como o movimento estava sendo organizado. Até o momento, o processo se desenvolvia através de abaixo-assinados, passeatas, manifestações, reuniões e debates. A partir de uma cartilha que explicava como organizar uma ocupação, e mencionava o caso chileno, surgiu a ideia.

Em 2006, no Chile, jovens estudantes secundaristas iniciaram um movimento reivindicando passe livre estudantil grátis e sem restrições de horário, melhorias na merenda escolar, reformas nas instituições de ensino e gratuidade do exame de seleção para a universidade (ZIBAS, 2008, p. 201). Essa mobilização estudantil foi adquirindo dimensões nacionais, agregando outros atores políticos

\footnotetext{
${ }^{3}$ Este documentário foi idealizado e produzido por Carlos Pronzato (cineasta argentino), Lucas Duarte (professor e videoativista) e Caio Finato (videodocumentarista). Segundo os produtores, o objetivo do vídeo é registrar e manter viva essa luta estudantil que repercutiu por todo o país. O lançamento ocorreu em fevereiro de 2016 através do Youtube, disponível no link: <https://www.youtube.com/watch?v=LK9Ri2prfNw>. Acesso em: 15 jan. 2017.
}

Revista Teias v. 18, n. 50, 2017 (Jul./Set.): Conversas sobre formação de professores, práticas e currículos 
nas disputas (como empresários da educação, o sindicato dos professores, universitários), e mobilizou o governo de Michelle Bachelet a organizar reuniões e negociar alterações educacionais ${ }^{4}$. O que passou a ser foco de discussões foi a LOCE (Lei Orgânica Constitucional da Educação), que foi instituída nos últimos momentos do governo ditatorial de Pinochet e seguiu sendo implementada nos posteriores governos democráticos.

O modelo educacional chileno instituído pela LOCE possui uma perspectiva neoliberal, pois privilegia as escolas particulares em detrimento das públicas. Há uma descentralização da gestão educacional e o Estado paga subsídios às escolas particulares, que também possuem autorização para cobrar mensalidades das famílias ou a selecionarem quais seriam os estudantes que estariam aptos a frequentarem as suas aulas. Dessa forma, as escolas municipais (públicas) foram sendo sucateadas com o passar dos anos.

Essa experiência chilena também resultou em um documentário intitulado de "A Revolta dos Pinguins" ", pois os estudantes secundaristas chilenos são apelidados de pinguins devido ao seu uniforme, que é composto de camisa branca com colete e gravata pretos. Esse documentário, cartilhas e materiais publicados e difundidos pela internet proporcionaram uma rápida transmissão de ideias e modos de fazer dessas mobilizações estudantis.

Sendo assim, é possível perceber a proximidade que os jovens possuem com as tecnologias e suas linguagens: fotos, blogs, vídeos, documentários, cartilhas, grupos de discussões, redes sociais são alternativas para divulgar os posicionamentos dos jovens secundaristas, pois os sujeitos que estão nas mobilizações são os mesmos que produzem esses materiais informativos. Dessa forma, não há uma procura pela "grande mídia" (jornais impressos, rádio, programas de televisão) e pode haver a possibilidade dos estudantes se contraporem ou discordarem de alguma informação veiculada por essa imprensa tradicional.

As primeiras ocupações brasileiras ocorreram em São Paulo. O governo paulista anunciou em setembro de 2015 uma reorganização da rede pública, em que as escolas seriam organizadas por ciclos únicos. Dessa forma, não haveria mais estabelecimentos com turmas de ensino fundamental e

\footnotetext{
${ }^{4}$ Inclusive com repercussões negativas para o governo, como a demissão do Ministro da Educação chilena. Para maiores detalhes sobre essa mobilização dos estudantes, ver (ZIBAS, 2008, p. 203).

5 O documentário "A Revolta dos Pinguins" também é uma produção de Carlos Pronzato sobre os movimentos estudantis ocorridos no Chile em 2006. Esse vídeo foi ganhador do Prêmio Especial do Júri na XXXVI Jornada Internacional de Cinema da Bahia (2009) e do Prêmio Internacional Roberto Rossellini, no Festival de Maiori, na Itália (2009). Da mesma forma que o documentário sobre as ocupações de São Paulo, esse vídeo está disponível no Youtube para ser assistido e divulgado de forma gratuita através do link: 〈https://www.youtube.com/watch?v=tetACHaxxJU>. Acesso em: 14 jan. 2017.
} 
médio, possibilitando que o aluno desenvolvesse sua trajetória escolar em uma única instituição. Com esta reorganização, 94 escolas estaduais deixariam de funcionar e os alunos matriculados seriam encaminhados para outras escolas estaduais. Diante da informação de execução desse planejamento, que não foi discutido antes com as comunidades escolares desses locais que seriam fechados, surgiu o movimento "Não fechem a minha escola".

As ocupações podem ser planejadas a partir de pesquisas na Internet, seja pelos documentários mencionados acima ou pela leitura e estudo de cartilhas que orientam como organizar uma ocupação escolar. Dessa forma, em novembro de 2015, a primeira escola paulista foi ocupada (Escola Estadual Fernão Dias) e logo depois outras seguiram o movimento. A escola elaborada e organizada por eles é distinta não pela falta de professores, funcionários e equipe diretiva. Essas experiências de ocupações se diferenciam pela apropriação dos espaços pelos jovens e por suas culturas juvenis.

Considerando os conceitos de Certeau (1998), a ocupação das escolas pode ser entendida como uma tática encontrada pelo movimento estudantil para chamar atenção para suas demandas e reivindicações. Se o governo utilizou a estratégia do discurso de reorganização e reestruturação do sistema público escolar a partir do fechamento das escolas (que reforçando o processo de sucateamento do ensino público), uma das táticas pensadas pelos jovens estudantes foi reutilizar esses espaços educacionais de maneira distinta, ocupando e reelaborando as atividades educacionais a partir deles, sujeitos educandos.

Adotar os conceitos de tática e estratégia permite demonstrar que os alunos não são consumidores passivos da escola, mas também, produtores do processo educativo. Segundo Certeau (1998), os consumidores culturais são também produtores. Essa afirmação reforça a imagem social dos jovens como questionadores e transformadores da sociedade. À vista disso, é importante salientarmos que a atuação juvenil não é um fenômeno recente, e que os jovens vêm desenvolvendo importante papel na sociedade ao longo do tempo.

\section{3. "NÃO CONFIE EM NINGUÉM COM MAIS DE TRINTA ANOS": ATUAÇÕES JUVENIS AO LONGO DA HISTÓRIA.}

A música "Com mais de trinta", do compositor Marcos Valle, remete a um contexto histórico da década de 1960 e 1970 quando surgiram diferentes manifestações e revoluções pelo mundo organizadas e lideradas por jovens, sujeitos que tinham menos de trinta anos. As transformações eram econômicas, políticas, comportamentais, sexuais. Os jovens desejavam mudar o mundo que receberam de seus progenitores. 
Ao estudarmos as ocupações, surgiram algumas questões referentes à atuação dos jovens na sociedade em que estão inseridos. Seriam os jovens fruto do meio social no qual se inserem? Seriam os jovens sujeitos passivos das mudanças políticas que ocorrem na sociedade? Qual a importância da atuação juvenil? Para responder estes questionamentos, decidimos pensar a atuação dos jovens em diferentes momentos históricos.

Segundo Mario Sandoval (2012, p. 46), as diferentes revoluções ocorridas no mundo podem ser pensadas a partir da atuação juvenil, principalmente a partir da década de 1950. A revolução cubana, por exemplo, tem suas origens em 1953, com a atuação de guerrilheiros opositores à ditadura de Fulgêncio Batista, e que eclodirá no processo político e militar de $1^{\text {o }}$ de janeiro de 1959. Analisando as idades de alguns dos membros que atuaram em uma expedição de 1956, que tinha por finalidade ingressar clandestinamente em Cuba, o autor destaca: “[...] en esa fecha Fidel Castro tênia 30 años, el Che Guevara 28 años, Raúl Castro 25 años, Camilo Cienfuegos 24 años, Ramiro Valdés 24 años y Juan Almeida 29” (SANDOVAL, 2012, p. 46).

Além do caso cubano, o autor discute a atuação juvenil na sociedade a partir de outros momentos históricos. No "Maio Francês", episódio ocorrido no mês de maio de 1968, milhares de jovens saíram nas ruas da França protestando. Na época, um dos principais líderes, Daniel Cohn Bendit, tinha 23 anos. Sobre a atuação dos jovens nesse contexto, o autor destaca que estavam motivados pelo desejo de mudar a forma de viver do país. Sobre esse contexto, Maria Maciel argumenta que as contestações e revoluções ocorridas em 1968 não instauraram nenhum novo tipo de governo pelo mundo, mas colocaram novamente a juventude (ou uma parte dela) na posição de contestação e quebra de acordos sociais estabelecidos, nas mudanças dos “costumes", na criação de uma contracultura.

Assim, por este número - 68 - englobam-se acontecimentos que irrompem quase ao mesmo tempo em diversas partes do mundo e que tinham na juventude seu contingente mais importante. Como movimento de juventude, encontra-se dentro dos quadros de rebeldia e inconformismo que já estavam sendo gestados anteriormente. Embora os acontecimentos tenham irrompido em vários países, cada qual assumindo formas particulares e singulares em decorrência das condições dadas em cada lugar, a ideia de transformação social, de mudança revolucionária e do socialismo foram colocadas na ordem do dia (MACIEL, 2003, p. 36).

Também no ano de 1968, em 27 de agosto, Mario Sandoval (2012, p. 47) destaca que se sucedeu no México em protesto contra o governo de Gustavo Diaz Ordaz, uma marcha de mais de 200.000 estudantes. De acordo com o autor, os protestos juvenis adentram o mês de outubro, resultando na morte de centenas de estudantes pelo exército mexicano. 
Assim como em Cuba, na França e no México, os jovens protagonizaram também movimentos na Argentina (Movimento Estudantil de 1969), Nicarágua (Revolução de 1979), na China (protestos na Praça Tiananmen, de 1989), na Alemanha ("Derrubada" do Muro de Berlim, em 1989) e em muitos outros países. Embora aborde diferentes locais e diferentes momentos da atuação juvenil, o autor não retrata o protagonismo dos jovens brasileiros. Teriam os nossos jovens atuação política direta?

Dentre diferentes momentos da história do Brasil nos quais os jovens exerceram significativa influência, destacamos neste estudo a atuação deles durante a ditadura civil-militar, que tem início com o golpe de 1964 e se estende ao longo dos anos 1980, com o processo de abertura política. De acordo com Santos (2009, p. 104), durante a ditadura civil-militar, diferentes movimentos populares foram reprimidos, em especial o Movimento Estudantil. Segundo a autora, a atuação dos estudantes intensifica-se principalmente durante o ano de 1968, marcado por episódios como a "Passeata dos Cem Mil", a "Batalha da Rua Maria Antonia" e a realização do XXX Congresso da União dos Estudantes (UNE), realizado em Ibiúma, São Paulo. Estes episódios são fortemente marcados pela presença de líderes juvenis, como Vladimir Palmeira, José Dirceu e Luis Tavares, que militavam em diferentes organizações.

Como observa a autora, a perseguição aos jovens líderes dos movimentos em oposição ao regime intensifica-se a partir da promulgação do Ato Institucional n ${ }^{\circ} 5$ (AI-5). Com a intensificação da censura e repressão, líderes estudantis e partidários foram presos, mortos e torturados. Dentre os mortos destacamos Honestino Guimarães (desaparecido em 1973, com 26 anos) e Alexandre Vanucchi Leme (líder estudantil da USP, morto em 1973, com 23 anos).

A atuação dos jovens durante a ditadura é simbolicamente retomada por aqueles que têm atuado nas atuais ocupações das escolas em 2015 e 2016. É importante destacar um evento que ocorreu durante as ocupações das escolas secundárias gaúchas. A Escola Estadual Presidente Costa e Silva, localizada em Porto Alegre, foi ocupada no dia 16 de maio. No dia seguinte, os jovens ocupantes decidiram trocar o nome da instituição para Escola Estadual Edson Luís, homenageando o primeiro estudante morto durante o contexto da ditadura civil-militar brasileira, em 1968.

Portanto, a partir das reflexões dos autores mencionados é possível afirmar que o protagonismo juvenil não está restrito ao contexto atual. Diferentes sujeitos buscaram melhorias ou transformações radicais em momentos distintos da história mundial e nacional. Agora, a manifestação acontece dentro da escola, ocupando os espaços escolares para chamar a atenção às reivindicações por melhores condições educacionais. Mas como ocorre uma ocupação? Como os 
jovens se articulam? Essas respostas podem ser respondidas a partir da análise de três cartilhas, que estão disponíveis para estudo e planejamento das ocupações. Essas cartilhas, além de serem orientadoras do processo, possibilitam pensar outras formas de utilizar o espaço escolar.

\section{4. “OCUPAR E RESISTIR”: TRANSFORMANDO O ESPAÇO ESCOLAR}

Algumas autoras (CORTI, 2009; KRAWCZYK, 2014; KUENZER, 2000; MOLL; GARCIA, 2014; ZIBAS, 2005) argumentam que a escola, principalmente a escola secundária, deve passar por modificações de maneira a reconhecer os sujeitos que estão em suas salas de aula. $\mathrm{O}$ ensino secundário brasileiro nas últimas décadas abarcou novos segmentos sociais e ocorreram descompassos entre o antigo ensino propedêutico e os novos jovens estudantes com suas diferentes vivências e trajetórias, suas culturas juvenis. Não é à toa que a evasão escolar, a distorção idadesérie e a repetência são desafios a serem superados em todo o país com relação ao ensino médio.

Sobre as culturas juvenis, Dayrell (2001, p. 139) argumenta que a escola é uma instituição que homogeneíza os sujeitos que estão frequentando seus espaços através de categorias abrangentes como "professores", “alunos", "funcionários”. No que diz respeito aos "alunos":

Assim, independentes do sexo, da idade, da origem social, das experiências vivenciadas, todos são considerados igualmente alunos, procuram a escola com as mesmas expectativas e necessidades. Para esses professores, a instituição escolar deveria buscar atender a todos da mesma forma, com a mesma organização do trabalho escolar, mesma grade e currículo. A homogeneização dos sujeitos como alunos corresponde à homogeneização da instituição escolar, compreendida como universal (DAYRELL, 2001, p. 139).

Essa homogeneização desconsidera que os alunos são sujeitos socioculturais, jovens que possuem trajetórias de vida, escalas de valores, sentimentos, emoções e experiências que os diferenciam entre si. Se a cultura pode ser entendida como uma teia de significados, como um sistema entrelaçado de signos interpretáveis (GEERTZ, 1989, p. 81), então torna-se importante reconhecer esses jovens que adentram a escola como sujeitos que estão inseridos em culturas juvenis, em contextos de significados que podem ser descritos e interpretados e que merecem reconhecimento por parte dos professores e funcionários que estão trabalhando e convivendo com esses sujeitos. Segundo Juarez Dayrell:

São essas experiências, entre outras, que constituem os alunos como indivíduos concretos, expressões de um gênero, raça, lugar e papeis sociais, de escalas de valores, de padrões de normalidade. É um processo dinâmico, criativo, ininterrupto, em que os indivíduos vão lançando mão de um conjunto de símbolos, reelaborando-os a partir das suas interações e opções cotidianas. Dessa forma, esses jovens que chegam à escola são o resultado de um processo educativo amplo, que ocorre no cotidiano das relações sociais, quando os sujeitos

Revista Teias v. 18, n. 50, 2017 (Jul./Set.): Conversas sobre formação de professores, práticas e currículos 
fazem-se uns aos outros, com os elementos culturais a que têm acesso, num diálogo constante com os elementos e com as estruturas sociais onde se inserem e as suas contradições. Os alunos podem personificar diferentes grupos sociais, ou seja, pertencem a grupos de indivíduos que compartilham de uma mesma definição de realidade, e interpretam de forma peculiar os diferentes equipamentos simbólicos da sociedade. Assim, apesar da aparência de homogeneidade, expressam a diversidade cultural: uma mesma linguagem pode expressar múltiplas falas (DAYRELL, 2001, p. 142).

À vista disso, as ocupações escolares podem ser analisadas a partir das culturas juvenis. Se os jovens ocupam a escola e ressignificam seus espaços, a maneira como será organizada e gerida essa nova escola vai levar em consideração os olhares desses alunos ocupantes, esses meninos e meninas que estão repensando o espaço educacional. Esse repensar inclui a forma de conceituar essas manifestações. Ocupar a escola não é invadi-la. Os próprios jovens afirmam que eles não são invasores. Primeiro porque o espaço pertence a eles, são estudantes da instituição. Segundo porque essa atitude é política, ocupar um estabelecimento de ensino é respeitar o espaço, não destruí-lo, é estar disposto a reinterpretá-lo e vivenciar momentos especiais, em que há um constante repensar: das atitudes, das vivências, das negociações, das conversas entre si e com os demais sujeitos da comunidade escolar.

Com relação a como organizar e começar uma ocupação, os jovens apostam mais uma vez na rapidez e facilidade de divulgação da internet. Há diferentes versões de cartilhas ou manuais orientando como ocupar uma escola. Para esse artigo, analisamos três versões, sendo uma encontrada em um blog e duas postadas na página do Facebook "Escolas Gaúchas em luta". Dessas três cartilhas, duas foram feitas durante o contexto de São Paulo e uma foi organizada para o contexto gaúcho (sendo essa maior, com oito páginas, e orientando para outras formas de mobilizações, como manifestações de rua). A tabela abaixo apresenta a quantidade de páginas de cada cartilha.

TABELA 1. CARTILHAS DE ORIENTAÇÃO E PROCEDIMENTOS DE COMO OCUPAR UMA ESCOLA.

\begin{tabular}{|l|l|}
\hline Cartilha & Páginas \\
\hline COMO OCUPAR UM COLÉGIO? Manual escrito por estudantes secundaristas da & 8 \\
Argentina e Chile & \\
\hline Como ocupar sua Escola? & 3 \\
\hline Como ocupar sua Escola? & 1 \\
\hline
\end{tabular}

Fonte: elaborado pelos autores.

\footnotetext{
${ }^{6}$ Sendo que essa cartilha possui versão online e para impressão. Disponível em: <https://gremiolivre.wordpress. com/2015/10/21/como-ocupar-um-colegio-versao-online/>. Acesso em: 13 jan. 2017.
}

Revista Teias v. 18, n. 50, 2017 (Jul./Set.): Conversas sobre formação de professores, práticas e currículos 
De maneira geral, as três cartilhas apresentam oito aspectos a serem planejados para uma ocupação: o primeiro enfoca a assembleia, indicando que é o espaço de discussão e tomada de decisões pelo grupo. A horizontalidade é um dos pontos importantes desse movimento. Não há uma liderança definitiva, porém todos influenciam e participam dos rumos que a ocupação vai percorrer. A comunicação interna é o segundo aspecto, relacionado com essa perspectiva de horizontalidade. Uma comissão de comunicação interna deve ser organizada e as decisões precisam estar disponíveis para todos os jovens, mesmo para aqueles que não compareceram às assembleias. A sugestão de duas cartilhas é a confecção de cartazes a serem espalhados pela escola.

O terceiro ponto são as atividades culturais ${ }^{7}$, que podem ser oficinas, debates políticos, sessões de cinema, teatro, músicas, atividades que contribuam para a formação daqueles que estão na ocupação e também como forma de agregar mais estudantes e fortalecer o movimento. O quarto ponto enfocado é o da comida, sendo importante a organização de uma comissão responsável por essa parte, tanto para o controle do estoque de mantimentos, preparação das refeições e organização de pedidos e solicitações de doações. As pessoas que apoiam os ocupantes podem doar mantimentos ou produtos de limpeza, sendo que essas doações não precisam ser somente de pessoas pertencentes à comunidade escolar local.

O quinto aspecto refere-se à segurança, indicando que a comissão de segurança deve ser a primeira a ser organizada. A importância é garantir tanto a integridade física dos jovens quanto a integridade do patrimônio escolar, evitando que processos por depredação do patrimônio público ocorram. A comissão de segurança torna-se responsável por controlar a entrada e saída das pessoas que estão na instituição, sendo que uma prática comum é a solicitação do número do CPF daqueles que estão permanecendo ou visitando a escola ocupada.

É interessante destacar que a cartilha feita para as ocupações gaúchas orienta que todas as comissões devem ter homens e mulheres participando, independente da atividade. A ideia defendia é: "Lugar de menina é na segurança e de menino na limpeza, sim". A limpeza é o sexto ponto a se destacado, pois é importante deixar tudo organizado e evitar a bagunça.

A comunicação reaparece mais uma vez, todavia o enfoque é para o público externo. A comissão de comunicação deve produzir material próprio para divulgar através da internet.

\footnotetext{
${ }^{7}$ Essas atividades culturais podem contar com apoio de pessoas de fora da escola. Inclusive, uma das formas de ajudar as ocupações é doando uma aula. Há um endereço eletrônico para o preenchimento dos dados de quem está disposto a ajudar nas ocupações e doar uma aula (https://docs.google.com/forms/d/1QT4-Jq7lyYhh9zIZ5hkOoJe6-DiT1t9co BNd4WDMBTk/viewform?c=0\&w=1). Nota-se nas escolas a presença de estudantes universitários como "oficineiros", promovendo diferentes debates e aulas diversificadas.
} 
Indicando que a "grande mídia" distorce a luta dos jovens ocupantes, é necessário a produção de material próprio para divulgação online e através das páginas ou sites voltados para esse movimento. Por fim, o apoio da comunidade escolar e de advogados é importante para resistir e enfrentar os grupos contrários à ocupação. Inclusive a cartilha gaúcha divulga um número de celular que pode ser usado em caso de dúvidas ou de necessidade de auxílio jurídico.

No que concerne às ocupações gaúchas, a próxima sessão apresentará algumas informações dessas ocupações que foram retiradas da Internet, de páginas da rede social Facebook, que são porta-vozes dos movimentos estudantis daqui. Além disso, mencionaremos alguns eventos importantes que ocorreram até o momento de elaboração desse trabalho.

\section{5. \#OCUPATUDORS: AS OCUPAÇÕES ESCOLARES NO RIO GRANDE DO SUL}

Conforme já mencionado, o fluxo de informações é constante e se dá através da internet. O Facebook e o Whattsapp tornam-se os dois meios de articulação entre estudantes e apoiadores, bem como entre os jovens ocupantes de escolas secundárias distintas. Contudo, o Facebook torna-se o mecanismo principal de divulgação de notícias e informações sobre as ocupações para a população que não está diretamente envolvida com o movimento.

Com relação ao Rio Grande do Sul, podemos dizer que há quatro páginas importantes ${ }^{8}$, que agregam informações de todas as ocupações escolares: “Ocupa Tudo RS”, "Escolas Gaúchas em Luta", "Escolas de Luta RS" e "Ocupa Mídia", sendo esta última uma página destinada à divulgação dos eventos e das necessidades dos jovens ocupantes. Além dessas páginas, boa parte das escolas ocupadas também possui uma própria, intitulada "Ocupa [nome da escola]", onde divulga os cronogramas das oficinas que estão ocorrendo naquela instituição, bem como apresenta as atividades desenvolvidas com os jovens que estão envolvidos com a ocupação.

Sobre a quantidade de instituições escolares ocupadas no estado, os dados informados pela Secretaria de Educação do RS (SEDUCRS) não coincidem com os dados apresentados pelos jovens. De acordo com a SEDUCRS, seriam 110 estabelecimentos ocupados, porém considerando

\footnotetext{
${ }^{8}$ Torna-se difícil afirmar quem coordena essas páginas citadas e elabora os conteúdos a serem postados. A intenção é manter o anonimato para evitar represálias, repreensões ou processos jurídicos. Ao mesmo tempo, a possibilidade de divulgar informações e atingir diferentes públicos é interessante para os estudantes. Para termos uma ideia da possibilidade de pessoas que estão interessadas nas informações veiculadas por essas páginas, a página "Ocupa Tudo RS" (https://www.facebook.com/ocupatudors/?fref=ts) possui 17.817 curtidas, "Escolas Gaúchas em Luta" (https://www.facebook.com/OcupaEscolaRS/?fref=ts) possui 8.687 curtidas, "Escolas de Luta RS" (https://www. facebook.com/escolasdelutaRS/?fref=ts) está com 10.007 curtidas e, por fim, "Ocupa Mídia" (https://www.facebook. com/OcupaMidia/?fref=ts) tem 2.887 curtidas. A contagem ocorreu no dia 05 de julho de 2016. Não podemos afirmar se todas as pessoas que curtiram essas páginas são distintas, por isso não realizamos um somatório de todas as páginas.
}

Revista Teias v. 18, n. 50, 2017 (Jul./Set.): Conversas sobre formação de professores, práticas e currículos 
as informações postadas na página "Ocupa Tudo Brasil”, seriam 157 escolas ocupadas. A tabela abaixo apresenta os municípios com mais de uma escola ocupada ${ }^{9}$ :

TABELA 2. MUNICÍPIOS DO RS COM MAIS DE UMA ESCOLA OCUPADA.

\begin{tabular}{|l|l|}
\hline Município & Quantidade \\
\hline Bagé & 2 \\
\hline Cachoeira do Sul & 4 \\
\hline Cachoeirinha & 3 \\
\hline Canoas & 3 \\
\hline Caxias do Sul & 4 \\
\hline Cruz Alta & 6 \\
\hline Esteio & 2 \\
\hline Gravataí & 2 \\
\hline Guaíba & 2 \\
\hline Não-me-Toque & 2 \\
\hline Novo Hamburgo & 4 \\
\hline Porto Alegre & 39 \\
\hline Pelotas & 7 \\
\hline Passo Fundo & 11 \\
\hline Rio Grande & 10 \\
\hline Rosário do Sul & 3 \\
\hline Santa Cruz do Sul & 3 \\
\hline Santa Maria & 2 \\
\hline Santo Ângelo & 2 \\
\hline São Leopoldo & 3 \\
\hline Sapucaia do Sul & 2 \\
\hline Uruguaiana & 2 \\
\hline Viamão & 3 \\
\hline Fonte: (OCUPA & \\
\hline
\end{tabular}

Fonte: (OCUPA..., 2017).

A primeira escola ocupada no estado foi o Colégio Estadual Coronel Afonso Emílio Massot, localizado em Porto Alegre. O movimento iniciou dia 11 de maio, de forma pacífica, com o grêmio estudantil e demais jovens ocupando duas salas de aula. A princípio, acordos foram feitos com a direção e as aulas seriam mantidas. Contudo, com o passar dos dias e o crescimento do movimento de ocupações dentro de Porto Alegre e no interior do estado, a escola foi totalmente ocupada e as aulas foram interrompidas. As reivindicações desses jovens do Colégio Emílio Massot seriam: falta

\footnotetext{
${ }^{9}$ Para que a tabela não fosse extensa demais, optou-se por retirar os municípios que foram indicados somente com uma escola ocupada. Segue a relação destes aqui: Alegrete, Ametista do Sul, Caçapava do Sul, Carazinho, Canguçu, Cidreira, Charqueadas, David Canabarro, Ernestina, Erval Grande, Guaporé, Herval, Igrejinha, Ijuí, Jaguari, Jaguarão, Joia, Lajeado, Marau, Montenegro, Nova Santa Rita, Novo Barreiro, Osório, Palmeiras das Missões, Santana do Livramento, Santa Rosa, Santa Vitória do Palmar, São Domingos do Sul, São Gabriel, São José do Norte, São Lourenço do Sul, Soledade, Taquara, Venâncio Aires, Vera Cruz, Veranópolis.
} 
de professores e funcionários, problemas de infraestrutura e sucateamento de mobiliário, atraso no repasse da autonomia financeira da instituição, parcelamento do salário dos professores.

O movimento dos jovens ocorreu em conjunto a outra mobilização: a greve dos professores estaduais. O CPERS (Centro dos Professores do Estado do Rio Grande do Sul), sindicato da categoria, deflagrou greve no dia 13 de maio. O parcelamento dos salários, a falta do reajuste salarial, o não pagamento do piso nacional dos professores, alguns projetos de lei que estão para serem votados (PL 190/15 e PL 44/16), as más condições das escolas e o não repasse das verbas estaduais são algumas reivindicações que levaram à decisão de greve dos professores estaduais.

Em um primeiro momento, era possível notar uma ausência da Secretaria da Educação do RS no assunto das ocupações. A ideia era que cada equipe diretiva das escolas conversassem e resolvessem a questão de maneira interna. Entretanto, a partir da terceira semana do mês de maio, o movimento cresceu e diversas escolas foram ocupadas pelos estudantes. O secretário de educação no período, Vieira da Cunha, estava em férias ${ }^{10}$ e retornou nos últimos dias de maio. Houve algumas visitas às escolas ocupadas, reuniões com os jovens, incluindo a recepção de uma comitiva de estudantes na SEDUCRS no dia primeiro de junho. Porém, nesse mesmo dia, Vieira da Cunha deixou o cargo de secretário da educação do estado.

As tratativas continuaram após a posse do novo secretário Luís Alcoba de Freitas. Os estudantes organizaram passeatas pelas cidades e, a partir das negociações com o governo, ocorreu a realização de uma assembleia geral no Colégio Protásio Alves, ${ }^{11}$ em Porto Alegre, para debater as propostas da SEDUCRS e organizar os próximos passos. Após essa assembleia, os jovens divulgaram uma nota relatando pontos a serem negociadas com o governo. No texto, os estudantes afirmam sua posição de diálogo e condenam o governo por negligenciar as demandas estudantis: “Por que não nos ouvir? Por que não priorizar nossa educação?”, são perguntas que estão presentes nesse documento. Os estudantes reafirmaram nessa nota suas reivindicações: a criação de uma Comissão de Fiscalização para acompanhamento das obras de infraestrutura nas escolas; o aumento

\footnotetext{
${ }^{10}$ Sobre as férias do secretário, dois comentários surgiram na época: o primeiro afirmava que o secretário estava descontente com as decisões do governador com relação à educação e por isso havia saído de férias para avaliar sua continuidade no cargo. O segundo alegava a vontade do secretário em tornar-se candidato à prefeitura de Porto Alegre, decidindo sair do cargo para concorrer às eleições municipais de 2016. No dia 01/06/2016, Vieira da Cunha definiu sua saída da SEDUCRS, deixando o cargo em meio ao movimento de ocupações.

${ }^{11}$ Mais uma vez a ideia de horizontalidade se faz presente no movimento das ocupações, pois essa assembleia contou com a participação de dezenas de estudantes de 45 escolas ocupadas.
}

Revista Teias v. 18, n. 50, 2017 (Jul./Set.): Conversas sobre formação de professores, práticas e currículos 
do valor estipulado pelo governo do RS para essas obras, ${ }^{12}$ o compromisso do governo em não promover retaliações aos estudantes (como a transferência de jovens ocupantes), uma maior fiscalização tanto do repasse do valor da merenda escolar quanto do cardápio a ser oferecido aos alunos; a nomeação e a contratação de professores que estão faltando e, por fim, a retirada de dois projetos de leis: o PL 190/15, intitulado "Escola sem Partido" e do PL 44/16, que abre espaço para que empresas façam investimentos nas escolas públicas, correndo o risco de haver uma privatização do ensino.

Podemos afirmar que dois acontecimentos foram importantes nesse mês de lutas e ocupações. O primeiro ocorreu logo após a divulgação da nota dos estudantes, no dia 13 de junho, segunda-feira, quando um grupo de jovens ocupou o saguão da Assembleia Legislativa do RS (em Porto Alegre). A escolha do local ocorreu devido à votação do PL 44/16, que seria na terça-feira, na Comissão de Constituição e Justiça. Após um dia de ocupação na Assembleia Legislativa e pressão para negociações, os estudantes desocuparam o espaço com a promessa de um acordo que seria firmado entre o governo e os jovens secundaristas. Na quarta-feira o acordo foi realizado, o governo do RS se comprometeu a cumprir algumas demandas solicitadas pelos jovens e os estudantes secundaristas assinaram o acordo e aceitaram desocupar as escolas.

Este acordo pode ser lido na página "Escolas Gaúchas em luta" e foi organizado em sete pontos. O primeiro confirmava a criação de um fórum permanente para a melhoria da educação pública gaúcha, com a participação da sociedade e dos estudantes. As reuniões aconteceriam na última quarta-feira de todo mês. O segundo ponto englobava as obras nas instituições de ensino, sendo que o governo se empenhava em repassar os R $\$ 40$ milhões prometidos até o dia 30 de junho. Maiores quantias estavam para ser discutidas no fórum permanente, de acordo com as condições financeiras estaduais. A merenda nas escolas era o terceiro ponto do acordo, com a fiscalização dos cardápios com a participação dos estudantes, bem como a promessa de aumento da verba para as merendas. A nomeação de professores para fechar os quadros que faltavam estava presente no ponto quatro. O quinto aspecto era o repasse das verbas atrasadas de autonomia financeira das escolas até o dia 20 de junho. O PL 44/2016 teve sua votação adiada até 2017, abrindo espaço para diálogo e discussões sobre este projeto no fórum permanente de educação. Por fim, o diálogo e o respeito foram reafirmados, buscando a não penalização ou represálias dos estudantes que participaram do movimento das ocupações.

\footnotetext{
${ }^{12} \mathrm{O}$ governo se comprometeu a repassar R $\$ 40$ milhões para obras e reformas nas escolas estaduais. Porém, dividindo essa quantia para aproximadamente 2.500 instituições de ensino estaduais, cada estabelecimento ganharia $\mathrm{R} \$ 16.000$, impossibilitando que estabelecimentos que necessitam de reformas mais profundas consigam realizar essas obras.
}

Revista Teias v. 18, n. 50, 2017 (Jul./Set.): Conversas sobre formação de professores, práticas e currículos 
Após a assinatura desse acordo e o compromisso em desocupar as escolas e retomar o ano letivo (mesmo que a greve dos professores estaduais não tenha sido encerrada), o movimento dos estudantes se dividiu. Um grupo de escolas de Porto Alegre, ${ }^{13}$ que se intitulavam de CEI (Comitê das Escolas Independentes) acusavam os estudantes que ocuparam a Assembleia Legislativa de não ouvir as demais escolas e tomar decisões pela maioria, desarticulando o movimento e não respeitando a horizontalidade defendida desde o início. Também acusavam que organizações como União Brasileira dos Estudantes Secundaristas (Ubes) e União Gaúcha dos Estudantes Secundaristas (Uges) estavam comandando as decisões e negociações com o governo, não deixando os próprios estudantes participarem e decidirem por si.

Diante dessa divisão dos secundaristas, e como forma de protesto do acordo feito com um grupo de estudantes mais representantes do governo do RS, o CEI ocupou a Secretaria da Fazenda no dia 15 de junho, com a ideia de conversar com o secretário da fazenda e indicar que havia dinheiro para ser repassados à educação. Essa ocupação resultou no episódio mais violento, até o momento, com relação ao movimento dos jovens. Mesmo que a SEDUCRS tenha divulgado uma nota oficial ${ }^{14}$ no dia 17 de maio afirmando que mobilizações estudantis não seriam tratadas como caso de polícia, os estudantes foram violentamente agredidos e retirados da Secretaria da Fazenda. Os menores de idade foram encaminhados à Delegacia de Polícia para Crianças e Adolescentes e os maiores de idade chegaram a passar horas no presídio central.

Após esse outro acontecimento que repercutiu de forma negativa para o governo do RS, outras negociações foram realizadas com o CEI e também foi fechado um acordo com esse grupo dissidente. Da mesma forma, uma nota por parte desses jovens foi divulgada na página "CEI Comitê das Escolas Independentes" onde eles afirmam os pontos acordados: a não criminalização das manifestações estudantis e nem qualquer tipo de punição dos jovens e professores envolvidos; paridade de cadeiras no fórum permanente para o CEI e uma quantia específica (entre $\mathrm{R} \$ 50.000$ a $\mathrm{R} \$$ 120.000) para reformas nas escolas que compõem este comitê. Os estudantes cedem nas reivindicações por passe livre estudantil e arquivamento da PL 44/16. Diante desse acordo, o último

\footnotetext{
${ }^{13}$ Não podemos afirmar quantas escolas realmente compunham o CEI. É possível afirmar que o Colégio Estadual Julio de Castilhos, o Colégio Estadual Cândido José de Godói, Colégio Estadual Florinda Tubino Sampaio, Instituto de Educação General Flores da Cunha são algumas instituições que compõem. O CEI afirma que ao todo são formados por 18 escolas ocupadas.

${ }^{14}$ Esta nota oficial pode ser lida no site da SEDUCRS: <http://www.educacao.rs.gov.br/pse/html/noticias_det.jsp? $\mathrm{PAG}=5 \& \mathrm{ID}=16905>$. Acesso em: 15 jan. 2017. Dividida em cinco pontos, argumenta que a Secretaria de Educação sempre se mostrou aberta ao diálogo, compreende que as demandas estudantis são válidas, dá orientações para as escolas estaduais e suas coordenarias regionais da educação em como proceder para manter o acesso dos professores e alunos aos estabelecimentos de ensino, reafirma o respeito às legislações relativas aos adolescentes e destaca que o governo estadual está preocupado com a educação do RS.
}

Revista Teias v. 18, n. 50, 2017 (Jul./Set.): Conversas sobre formação de professores, práticas e currículos 
dia de ocupações foi dia 23 de junho. Na semana do dia 27 de junho, todas as escolas do estado estavam desocupadas.

Os acontecimentos relatados nesse artigo compõem uma parcela dos episódios decorrentes dessas ocupações escolares. Torna-se difícil apresentar todas as vivências e acontecimentos que ocorreram em cada instituição. Além das negociações com o governo do estado, todos os jovens ocupantes tiveram que discutir, negociar, conversar com os demais membros da comunidade escolar. As trajetórias de vida desses jovens que passaram por momentos de tensão não serão as mesmas. A compreensão de que a busca por melhores condições de vida e a ideia de que a organização em conjunto pode resultar em conquistas será um legado dessas manifestações. Ademais, essas ocupações podem contribuir para se pensar mais uma vez nas violências que o Estado emprega para acabar ou minimizar movimentos sociais (não sendo somente um episódio encontrado do RS, mas nos demais estados brasileiros e inclusive no Chile).

As ocupações no Rio Grande do Sul corroboram para a defesa da existência de uma juventude ativa, atuante e crítica ao meio social no qual se inserem. Embora exista a possibilidade de grupos políticos partidários estarem envolvidos em alguns episódios das ocupações, bem como a presença de sujeitos não mais tidos como “jovens”, a análise das notícias veiculadas pelas mídias aqui investigadas mostra a presença de um número significativo de representantes das juventudes brasileiras atuando por aquilo que acreditam. Os jovens não estão acomodados nem são uma massa amorfa. Muito pelo contrário. Estão reivindicando, lutando, estão ocupando.

Por fim, é importante ressaltar como os jovens aproveitam as tecnologias do momento. A internet proporciona uma rapidez de comunicação e divulgação de informações que facilita a coordenação dessas ocupações. Mais uma vez podemos utilizar o conceito de tática, que burla o status quo, pois esses estudantes, através do Whattsapp e Facebook, podem buscar exemplos externos, a partir das cartilhas, páginas da rede social ou documentários disponíveis, bem como divulgar seus posicionamentos e contrapor informações de veículos mais tradicionais, como jornais impressos, rádio e televisão. Apropriar-se dessas ferramentas para divulgar seus olhares e pensamentos, compor uma rede de apoio entre estudantes, pais, professores e incentivadores, ou utilizar esse espaço para a comunicação e divulgação são novidades que esse movimento das ocupações trouxe para o cenário da luta política por uma educação pública de qualidade. 


\section{REFERÊNCIAS}

ARIÈS, P. História Social da Criança e da Família. Rio de Janeiro: LTC, 1981.

BRASIL. Lei 12.852, de 5 de agosto de 2013. Diário Oficial da União, Brasília, DF, 6 ago. 2013. Disp.: <.http://www. planalto.gov.br/ccivil_03/Ato2011-2014/2013/Lei/L12852.htm>. Acesso em: 19 jun. 2016.

CERTAU, M. A Invenção do Cotidiano: Artes de Fazer. 3. ed. Vozes: Petrópolis, 1998.

CORTI, A. P. Uma diversidade de sujeitos: juventude e diversidade no Ensino Médio. Salto para o Futuro, Rio de Janeiro, ano 19, boletim 18, nov. 2009. Disp.: 〈http://portaldoprofessor.mec.gov.br/storage/materiais/0000012176.pdf〉. Acesso em: 14 jan. 2017.

DAYRELL, J. A Escola como Espaço Socio-Cultural. In: DAYRELL, J. (Org.). Múltiplos Olhares sobre educação e cultura. Belo Horizonte: UFMG, 2001. p. 136-161.

DAYRELL, J.; CARRANO, P. Juventude e Ensino Médio: quem é este aluno que chega à escola. In: DAYRELL, J.; CARRANO, P.; MAIA, C. (Org.). Juventude e Ensino Médio: sujeitos e currículos em diálogo. Belo Horizonte: UFMG, 2014. p. 101-133. Disp.: <http://educacaointegral.org.br/wp-content/uploads/2015/01/livrocompleto_juventude-e-ensino-medio_2014.pdf>. Acesso em: 10 jan. 2017.

GEERTZ, C. A Interpretação das Culturas. Rio de Janeiro: LTC, 1989.

KRAWCZYK, N. Uma roda de conversa sobre os desafios do ensino médio. Revisitando ideias e desalentos que os professores expressam. Será que as coisas são mesmo assim? Ou é possível vê-las por outro ângulo? In: DAYRELL, J.; CARRANO, P.; MAIA, C. (Org.). Juventude e Ensino Médio: sujeitos e currículos em diálogo. Belo Horizonte: UFMG, 2014. p. 75-100. Disp.: <http://educacaointegral.org.br/wp-content/uploads/2015/01/livro-completo_juventudee-ensino-medio_2014.pdf>. Acesso em: 10 jan. 2017.

KUENZER, A. Z. O Ensino Médio agora é para a vida: entre o pretendido, o dito e o feito. Educação \& Sociedade, Campinas, v. 21, n. 70, p. 15-39, abr. 2000. Disp.: 〈http://www.scielo.br/pdf/es/v21n70/a03v2170.pdf>. Acesso em: 3 jan. 2017.

LARANJEIRA, D.; IRIART, M.; RODRIGUES, M. Problematizando as Transições Juvenis na Saída do Ensino Médio. Educação \& Realidade, Campinas, v. 41, n. 1, p. 117-133, 2016. Disp.: <http://seer.ufrgs.br/index.php/ educacaoerealidade/article/view/56124/36233>. Acesso em: 8 jan. 2017.

MACIEL, M. E. Quando o mundo era jovem. In: HOLZMANN, L.; PADRÓS, E. S. (Ed.). 1968: contestação e utopia. Porto Alegre: Ed. da UFRGS, 2003. p. 40-53.

MARGULIS, M.; URRESTI, M. La juventud es más que una palabra. In: MARGULIS, M. (Ed.). La juventud es más que una palavra: Ensayos sobre Cultura y Juventud. Buenos Aires: Biblos, 2008. p. 20-36.

MOLL, J.; GARCIA, S. Prefácio. In: DAYRELL, J.; CARRANO, P.; MAIA, C. (Org.). Juventude e Ensino Médio: sujeitos e currículos em diálogo. Belo Horizonte: UFMG, 2014. p. 75-100. Disp.: <http://educacaointegral.org.br/wpcontent/uploads/2015/01/livro-completo_juventude-e-ensino-medio_2014.pdf>. Acesso em: 12 jan. 2017.

OCUPA Tudo RS. 2017. Disponível em: <https://www.facebook.com/ocupatudors>. Acesso em: 6 jan. 2017.

SANDOVAL, M. La desconfianza de los jóvenes: sustrato del malestar social. Ultima década, Valparaíso, v. 20, n. 36, p. 43-70, 2012. Disp.: <http://www.scielo.cl/pdf/udecada/v20n36/art03.pdf>. Acesso em: 3 jan. 2017.

SANTOS, J. A repressão ao Movimento Estudantil na Ditadura Militar. Revista AURORA, Marília, ano 3, n. 5, p. 101-108, 2009. Disp.: 〈http://www.marilia.unesp.br/Home/RevistasEletronicas/Aurora/SANTOS.pdf>. Acesso em: 22 dez. 2016.

ZIBAS, D. "A Revolta dos Pingüins" e o novo pacto educacional chileno. Revista Brasileira de Educação, Rio de Janeiro, v. 13, n. 38, p. 199-220, 2008. Disp.: 〈http://www.scielo.br/pdf/rbedu/v13n38/02.pdf〉. Acesso em: 21 dez. 2016.

ZIBAS, D. A reforma do ensino médio nos anos de 1990: o parto da montanha e as novas perspectivas. Revista Brasileira de Educação, Rio de Janeiro, n. 28, p. 24-36, 2005. Disponível em: <http://www.scielo.br/pdf/rbedu/n28/a03n28.pdf>. Acesso em: 22 dez. 2016. 


\section{RESUMO}

O estudo analisa a ocupação das escolas secundárias no estado do Rio Grande do Sul (Brasil) ocorridas em 2016, atentando para a atuação e o protagonismo dos jovens secundaristas. Utiliza-se o conceito "juventudes" pois os sujeitos são heterogêneos e plurais, membros de diferentes culturas e grupos identitários. A atuação juvenil é pensada como parte de um processo mundial onde os jovens vêm desenvolvendo significativo papel nas sociedades onde se inserem. A metodologia empregada consiste em revisão bibliográfica, análise de mídias utilizadas pelos jovens bem como de cartilhas para ocupação. Os referenciais teóricos estão relacionados ao estudo das juventudes e os resultados são parciais, abordando a atuação dos jovens envolvidos a partir da veiculação em canais como Facebook e Whatsapp.

Palavras-chave: Juventudes; Escolas Ocupadas; Atuação Juvenil

\section{"A LOT OF OCCUPATION": SCHOOL OCCUPATIONS AND YOUTH'S ACTING IN RIO GRANDE DO SUL (2016) ABSTRACT}

The study analyzes the occupation of secondary schools in the state of Rio Grande do Sul (Brazil) that happened in 2016, noting the role and the protagonism of youngsters secondarist. The concept "youths" is used because the subjects are heterogeneous and plural, members of different cultures and identity groups. The juvenile acting is thought as part of a global process where young people have been developing significant role in the societies where they belong. The applied methodology consists of literature review, analysis of media utilized by the youngsters as well as booklets for occupancy. The theoretical references are related to the study of youths and the results are partial, covering the acting of the young people involved from the serving on channels like Facebook and Whatsapp.

Keywords: Youths; Occupied schools; Youth Acting

Submetido em Nov./2016

Aceito em Jul./ 2017 